Proceedings

\title{
Volatile Organic Compounds Influence Pine Processionary Moth Behavior ${ }^{+}$
}

\author{
Jorge M. S. Faria ${ }^{1,2, *}$, Ana M. Rodrigues ${ }^{3}$ and Sriradha Bhattacharya ${ }^{4}$ \\ 1 INIAV, I.P., Instituto Nacional de Investigação Agrária e Veterinária, Quinta do Marquês, 2780-159 Oeiras, \\ Portugal \\ 2 MED, Mediterranean Institute for Agriculture, Environment and Development, Institute for Advanced \\ Studies and Research, Évora University, Pólo da Mitra, Ap. 94, 7006-554 Évora, Portugal \\ 3 Plant Metabolomics Laboratory, Instituto de Tecnologia Química e Biológica António Xavier (ITQB NOVA), \\ Av. da República, 2780-157 Oeiras, Portugal \\ 4 IRAMAT-CRP2A UMR 5060-CNRS-Université Bordeaux Montaigne, Maison de l'archéologie, Esplanade \\ des Antilles F-33607, Pessac Cedex, France \\ * Correspondence: fariajms@gmail.com \\ + Presented at the 1st International Electronic Conference on Entomology (IECE 2021), 1-15 July 2021; \\ Available online: https://iece.sciforum.net/.
}

Citation: Faria, J.M.S.; Rodrigues, A. M.; Bhattacharya, S. Volatile Organic Compounds Influence Pine Processionary Moth Behavior, in Proceedings of the 1st International Electronic Conference on Entomology, 1-15 July 2021, MDPI: Basel, Switzerland, doi:10.3390/IECE-10527

Published: 1 July 2021

Publisher's Note: MDPI stays neutral with regard to jurisdictional claims in published maps and institutional affiliations.

Copyright: (c) 2021 by the authors. Submitted for possible open access publication under the terms and conditions of the Creative Commons Attribution (CC BY) license (http://creativecommons.org/licenses /by/4.0/).

\begin{abstract}
The pine processionary moth (PPM), namely Thaumetopoea pityocampa or T. wilkinsoni, feeds on pine needles, causing defoliation and promoting tree decline. The production and emission of volatile organic compounds is one of the most effective plant defense mechanisms against herbivory. The present work reviewed available reports on the influence of plant volatiles on PPM behavior. Eighteen volatiles were reported to be detected by the PPM, to inhibit feeding and oviposition, or to reduce attraction to pheromones. High biological activities were reported for limonene or $\beta$-pinene enantiomers. Infested pines showed increased production of bornyl acetate, $\beta$-pinene and caryophyllene oxide. Uncovering the volatile cues that influence parasitic PPM behavior provides an important contribute to the establishment of safer pest management practices to control this pine pest.
\end{abstract}

Keywords: enantiomers; limonene; pest management; Pinus; terpenes; Thaumetopoea pityocampa; volatiles; $\beta$-pinene

\section{Introduction}

The pine processionary moth (PPM), namely Thaumetopoea pityocampa or T. wilkinsoni (Lepidoptera: Thaumetopoeidae), is a tree phytophagous insect that affects mainly Pinus and Cedrus spp. The PPM is considered one of the most destructive pine defoliators and can be found in South Europe, North Africa, Asia and the Middle East. As a probable result of global warming, its geographical distribution has been expanding northwards, endangering the vast European pine forests [1].

PPM life cycle shows two phases, an aerial phase comprising the egg, larvae and adult stages, and a below ground phase, during pupa development. The PPM emerges from underground in the summer, reproduces and oviposits in the branch tips of the upper crown of pine trees. As eggs hatch, the larvae begin to feed on pine needles and moult. By the fourth instar, the recognizable silken nests that characterize this pest have enlarged to the definitive winter nest. Fully grown larvae (fifth instar) emerge in the beginning of spring and seek out pupation sites in the soil, in long head-to-tail processions [2].

In addition to the severe impact on biodiversity and forest ecosystem health, the PPM has a dangerous societal impact due to its urticating hairs, produced from the third instar onwards, that cause strong allergic reactions in mammals. Its increasing dispersion in 
urban areas and recreational pine parks has led to several occurrences of public health problems and high economic losses, resulting in increasing public awareness [1].

\section{Emission of tree volatiles due to herbivory}

Over the past decade, tree defoliation was estimated to be over $20 \%$ in European forest ecosystems. Insect herbivore pests are key stress factors responsible for vegetation damage and have greatly contributed to the increase in defoliation estimates in several forest ecosystems worldwide. Herbivory greatly influences the amounts and classes of volatiles emitted by trees. Forest ecosystems are the largest source of atmospheric volatile organic compounds that play an important role in atmospheric chemistry and physics. The emitted volatiles are major players in plant communication, particularly plant-plant interaction, that promote defense responses, or plant-insect interactions (with either parasites or pollinators), as a direct defense mechanism [3]. These volatile emissions are comprised mainly of terpenoid compounds, well known modulators of insect development and behavior $[1,4,5]$.

In the present work, publications reporting on the influence of tree volatiles in PPM behavior and the induction/inhibition of pine volatile production as a result of PPM activity were reviewed.

\section{Reports on volatiles involving the pine processionary moth}

Published works reporting on the activity of tree volatiles on PPM behavior and the influence of PPM herbivory on pine volatile composition were compiled using Web of Science search engine, in all available databases, using the keywords "volatile" and "Thaumetopoea" or "processionary moth". The eight reports retrieved dated from 1999 to 2020 and were published in journals specialized in the scientific fields of Plant sciences (63\%), Entomology (25\%) and Environmental Sciences (25\%). These works generated 267 citations by a total of 240 works, in an average of 33 citations per work. The reports that cited these works were published in journals specialized in the scientific fields of Environmental Sciences (88 \%), Plant sciences (83\%) and Forestry (71 \%). Since 2011, the cumulative number of citations is steadily increasing, revealing a stable research interest in this field (Figure 1).

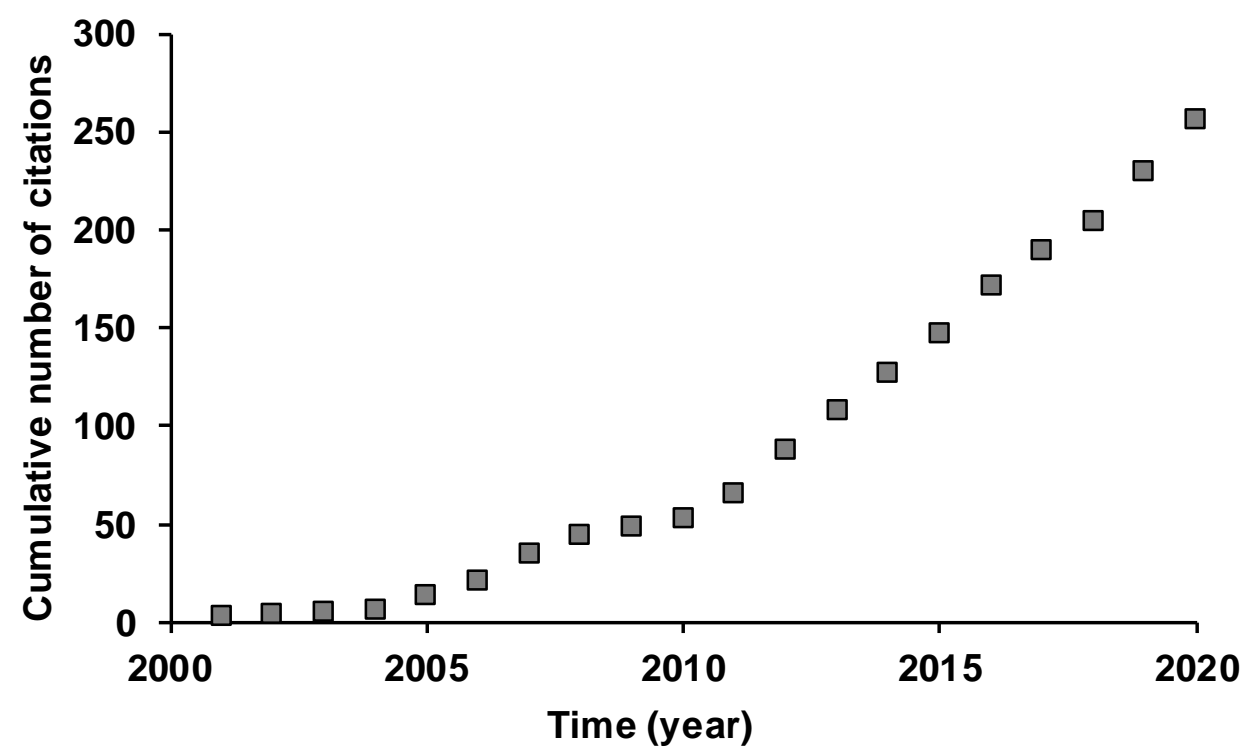

Figure 1. Cumulative number of citations of reports on volatiles involving the pine processionary moth. Data obtained from Web of Science (https://www.webofknowledge.com), using the keywords "volatile" and "Thaumetopoea" or "processionary moth".

\section{Effect of tree volatiles on the pine processionary moth}


The influence of tree volatiles on PPM behavior was analyzed in five reports. Zhang et al. [6] analyzed the potential role of pine emitted volatiles on host selection by PPM females, namely the response of $T$. pityocampa female antennae to volatiles from freshly cut Pinus sylvestris branches through coupled gas chromatographic-electroantennographic detection (GC-EAD). Surprisingly, a higher response was reported for pine volatiles commonly present in lower proportions, the monoterpenes $\beta$-myrcene, $\beta$-phellandrene, trans- $\beta$-ocimene, and terpinolene; while the more abundant pine volatiles induced no antennae response, namely the monoterpenes $\alpha$-pinene, $\beta$-pinene and $\delta$ - 3 -carene (Table 1). Additionally, a differential response was reported for limonene enantiomers, with the (-)-enantiomer eliciting a response but not the (+)-enantiomer. The effect of separate enantiomers was also analyzed by Tiberi et al. [7] and Panzavolta et al. [8], on PPM oviposition in host trees. Strong egg-laying deterrent properties were reported for (-)- $\beta$-pinene and (+)-limonene (Table 1). This limonene enantiomer was reported to provide a good degree of protection when applied in $P$. sylvestris, $P$. nigra, $P$. pinaster and $P$ radiata stands during T. pityocampa oviposition period.

Table 1. Tree volatile compounds reported to influence the behavior of the pine processionary moth.

\begin{tabular}{|c|c|}
\hline Compound & Activity $^{1}$ \\
\hline \multicolumn{2}{|c|}{ Monoterpene hydrocarbon } \\
\hline cis- $\beta$-ocimene & weak antennae response \\
\hline trans- $\beta$-ocimene & Strong antennae response \\
\hline (-)-limonene & $\begin{array}{c}\text { weak antennae response, inhibited oviposition, may } \\
\text { influence feeding }\end{array}$ \\
\hline (+)-limonene & $\begin{array}{l}\text { no antennae response, inhibited oviposition, may in- } \\
\text { fluence feeding }\end{array}$ \\
\hline terpinolene & Strong antennae response, may influence feeding \\
\hline$\alpha$-pinene & no antennae response, may influence feeding \\
\hline$\beta$-myrcene & Strong antennae response, may influence feeding \\
\hline$\beta$-phellandrene & Strong antennae response \\
\hline$(-)-\beta$-pinene & $\begin{array}{c}\text { no antennae response, inhibited oviposition, may in- } \\
\text { fluence feeding }\end{array}$ \\
\hline$(+)-\beta$-pinene & no antennae response, may influence feeding \\
\hline$\gamma$-terpinene & weak antennae response \\
\hline$\delta$-3-carene & no antennae response \\
\hline \multicolumn{2}{|c|}{ Sesquiterpene hydrocarbon } \\
\hline germacrene $\mathrm{D}$ & may influence feeding \\
\hline$\beta$-caryophyllene & may influence feeding \\
\hline \multicolumn{2}{|c|}{ Oxygenated sesquiterpene } \\
\hline $\begin{array}{l}\text { caryophyllene oxide } \\
\text { eudesmol }\end{array}$ & $\begin{array}{l}\text { may influence feeding } \\
\text { may influence feeding }\end{array}$ \\
\hline \multicolumn{2}{|l|}{ Branched chiral alcohol } \\
\hline 2-ethyl-1-hexanol & weak antennae response \\
\hline \multicolumn{2}{|l|}{ Phenylpropanoid } \\
\hline methyl salicylate & $\begin{array}{c}\text { Strong antennae response, inhibited male attraction to } \\
\text { pheromones }\end{array}$ \\
\hline
\end{tabular}

Petrakis et al. [10] analyzed the direct activity of terpenoid extracts from 15 pine species on the feeding behavior of T. pityocampa caterpillars, and developed an analytical model to predict the influence of each terpene compound. Although no constant promoter or inhibitor role could be attributed to any volatile throughout PPM feeding stages, the 
terpenes caryophyllene oxide, terpinolene, $\beta$-myrcene, germacrene $\mathrm{D}$, eudesmol, limonene, $\beta$-pinene, $\beta$-caryophyllene and $\alpha$-pinene allowed the construction of the most robust model, which suggests that these volatiles may influence the PPM feeding behavior.

Jactel et al. [9] analyzed the influence of volatiles from non-host species on the PPM, based on the premise that richer plant communities release diverse organic volatiles capable of disturbing host choice and mating behavior of predatory pests. Methyl salicylate, a birch emitted volatile, elicited antennae response and interfered with male PPM attraction to pheromone traps. This suggests that volatile chemical diversity plays an important role in natural forest pest management and can be used in sustainable strategies for PPM control.

\section{Effect of the pine processionary moth on tree volatiles}

Insect herbivory is known to induce strong chemical defenses in trees. The impact of PPM feeding on pine tissue volatile composition was profiled for five pine species, namely, P. nigra, P. pinaster, P. radiata, P. radiata and P. sylvestris. Variation in volatile compounds in pine after PPM feeding seems to be dependent on the pine species and respective volatile composition. For example, limonene was reported to increase in P. pinaster in response to PPM activity, whereas for $P$. radiata a reduction was reported (Table 2) [11]. Similarly, $\beta$-ocimene was reported to increase in $P$. nigra, while in P. sylvestris, cis- $\beta$-ocimene was reported to decrease $[12,13]$. Variability in volatile production after PPM herbivory seems to be dependent on the chemical defense strategy of each species, which suggests that there may not be a single defense mechanism in these conifers.

Table 2. Changes reported for pine volatile compounds as a response to herbivory by the pine processionary moth.

\begin{tabular}{cc}
\hline Compound & Pine Species $^{\mathbf{1}}$ \\
\hline Increase & $P$. pinaster \\
limonene & $P$. pinaster and $P$. radiata \\
$\beta$-pinene & $P$. nigra \\
$\beta$-ocimene & P. pinaster and $P$. nigra \\
bornyl acetate &
\end{tabular}

\begin{tabular}{cc} 
Decrease & \\
limonene & P. radiata \\
$\beta$-caryophyllene & $P$. sylvestris \\
germacrene D & $P$. sylvestris \\
bicyclogermacrene & $P$. sylvestris \\
$\alpha$-pinene & $P$. sylvestris \\
cis- $\beta$-ocimene & $P$. sylvestris \\
borneol & $P$. sylvestris \\
Epi-bicyclosesquiphelandrene & $P$. sylvestris \\
$\gamma$-muurolene & $P$. sylvestris \\
$\delta$-cadinene & $P$. sylvestris \\
$\tau$-cadinol & $P$. sylvestris \\
\hline${ }^{1}$ variation in pine volatiles reported in $[11-13]$.
\end{tabular}

${ }^{1}$ variation in pine volatiles reported in [11-13].

While $\beta$-pinene increased in $P$. pinaster and $P$. radiata after PPM feeding, $\alpha$-pinene decreased in $P$. sylvestris. Bornyl acetate was reported to increase in $P$. pinaster and $P$. nigra, however borneol decreased in P. sylvestris.

Surprisingly, many of the pine emitted volatiles that significantly changed in response to PPM herbivory (Table 2) were also reported to directly influence PPM behavior with respect to feeding, oviposition, and antennae response (Table 1); namely limonene, 
$\beta$-pinene, $\beta$-ocimene, germacrene $D$, and $\beta$-caryophyllene, suggesting an undiscovered volatile interplay between the PPM and its host.

\section{Conclusions}

Analysis of the volatiles with activity on the PPM and involved in the response to PPM induced defoliation is still preliminary. Nevertheless, the compilation of available research allowed to conclude that the volatile chemical responses of forest species, in particular those of pines, can greatly influence PPM behavior. A higher number of studies will be required to propose effective anti-PPM mechanisms that can contribute to understand PPM behavior and establish sustainable pest management strategies capable of efficiently protect forest ecosystems.

Author Contributions: Conceptualization, J.M.S.F.; methodology, J.M.S.F.; software, J.M.S.F.; investigation, J.M.S.F. and A.M.R.; writing - original draft preparation, J.M.S.F. and A.M.R.; writingreview and editing, J.M.S.F., A.M.R. and S.B. All authors have read and agreed to the published version of the manuscript.

Funding: This research received no external funding.

Institutional Review Board Statement: Not applicable.

Informed Consent Statement: Not applicable.

Conflicts of Interest: The authors declare no conflict of interest.

\section{References}

1. Paiva, M.R.; Mateus, E.; Santos, M.H.; Branco, M.R. Pine volatiles mediate host selection for oviposition by Thaumetopoea pityocampa (Lep., Notodontidae). J. Appl. Entomol. 2011, 135, 195-203, doi:10.1111/j.1439-0418.2010.01550.x.

2. Masutti, L.; Battisti, A. Thaumetopoea pityocampa (Den. \& Schiff.) in Italy Bionomics and perspectives of integrated control. J. Appl. Entomol. 1990, 110, 229-234, doi:10.1111/j.1439-0418.1990.tb00117.x.

3. Faiola, C.; Taipale, D. Impact of insect herbivory on plant stress volatile emissions from trees: A synthesis of quantitative measurements and recommendations for future research. Atmos. Environ. X 2020, 5, 100060, doi:10.1016/j.aeaoa.2019.100060.

4. López-Goldar, X.; Lundborg, L.; Borg-Karlson, A.K.; Zas, R.; Sampedro, L. Resin acids as inducible chemical defences of pine seedlings against chewing insects. PLoS ONE 2020, 15, e0232692, doi:10.1371/journal.pone.0232692.

5. Faria, J.M.S. Control of Thaumetopoea pityocampa and T. wilkinsoni with essential oils and respective volatile monoterpenoids. Proceedings 2021.

6. Zhang, Q.H.; Schlyter, F.; Battisti, A.; Birgersson, G.; Anderson, P. Electrophysiological responses of Thaumetopoea pityocampa females to host volatiles: Implications for host selection of active and inactive terpenes. Anzeiger fur Schadlingskd. 2003, 76, 103107, doi:10.1046/j.1439-0280.2003.03014.x.

7. Tiberi, R.; Niccoli, A.; Curini, M.; Epifano, F.; Marcotullio, M.C.; Rosati, O. The role of the monoterpene composition in Pinus spp. needles, in host selection by the pine processionary caterpillar, Thaumetopoea pityocampa. Phytoparasitica 1999, 27, 263272, doi:10.1007/BF02981482.

8. Panzavolta, T.; Tellini Florenzano, G.; Tiberi, R. Pine monoterpene deterrence of pine processionary moth oviposition. Urban For. Urban Green. 2015, 14, 538-543, doi:10.1016/j.ufug.2015.05.004.

9. Jactel, H.; Birgersson, G.; Andersson, S.; Schlyter, F. Non-host volatiles mediate associational resistance to the pine processionary moth. Oecologia 2011, 166, 703-711, doi:10.1007/s00442-011-1918-z.

10. Petrakis, P.V.; Roussis, V.; Papadimitriou, D.; Vagias, C.; Tsitsimpikou, C. The effect of terpenoid extracts from 15 pine species on the feeding behavioural sequence of the late instars of the pine processionary caterpillar Thaumetopoea pityocampa. Behav. Processes 2005, 69, 303-322, doi:10.1016/j.beproc.2004.12.008.

11. Moreira, X.; Lundborg, L.; Zas, R.; Carrillo-Gavilán, A.; Borg-Karlson, A.K.; Sampedro, L. Inducibility of chemical defences by two chewing insect herbivores in pine trees is specific to targeted plant tissue, particular herbivore and defensive trait. Phytochemistry 2013, 94, 113-122, doi:10.1016/j.phytochem.2013.05.008.

12. Foti, V.; Araniti, F.; Manti, F.; Alicandri, E.; Giuffrè, A.M.; Bonsignore, C.P.; Castiglione, E.; Sorgonà, A.; Covino, S.; Paolacci, A.R.; et al. Profiling volatile terpenoids from calabrian pine stands infested by the pine processionary moth. Plants 2020, 9, 122, doi:10.3390/plants9101362.

13. Achotegui-Castells, A.; Llusià, J.; Hódar, J.A.; Peñuelas, J. Needle terpene concentrations and emissions of two coexisting subspecies of Scots pine attacked by the pine processionary moth (Thaumetopoea pityocampa). Acta Physiol. Plant. 2013, 35, 3047-3058, doi:10.1007/s11738-013-1337-3. 